\title{
The Economic Analysis on the Electric Universal Services
}

\author{
Jianhui Liao \\ State Grid Energy Research Institute, SGCC Administrative Area, Future Science and Technology Park North Area, \\ Beiqijia Town, Changping, Beijing 102209, P.R. China
}

\begin{abstract}
The electricity universal service is an important public welfare policy. In this paper, the general economic analysis framework of electric universal service is constructed, the necessity of monopoly supply and government regulation is demonstrated, and the attribute of electricity universal service and the compensation scale of cost gap are analyzed. In addition, the paper also proposes two ideas to optimize the implementation mechanism of electric universal service.
\end{abstract}

Keywords-electric universal services; economic analysis; efficiency; compensation scale; sub-file price

\section{INTRODUCTION}

Up to now, universal service has become a more mature concept, and is widely used in postal services, electricity, telecommunications, education, health care, water supply and other fields. The universal service of various industries has basically formed a set of stable system, but there are still some problems, the main reason comes from the theoretical level and technical factors. Therefore, from the perspective of economics to explain the power industry's universal service, which is conducive to improving the operation of universal electricity service mechanism and implementation effect

\section{THE BASIC CONTENT AND CHARACTERISTICS}

The concept of universal service was originated in the United States telecommunications industry in the 1980s, and later promoted and applied to education, health care, transportation, postal services, power supply, water supply and other areas which are closely related to people's lives. Universal service refers to the fact that the state, in order to protect the basic rights and interests of all citizens and narrow the gap between the rich and the poor, through the enactment of laws and policies, makes all citizens irrespective of their income, whether living in any part of the country, including rural areas, remote areas or other high-cost areas, can at a generally acceptable price, access to the services for a basic needs and meeting the development.[1] Electricity is an important part of universal service. There are many literatures which summarize its basic connotation,[2][3][4] in short, electric universal service means that the state formulates policies and takes measures to ensure that all users have access to reliable and sustainable basic electricity services at a reasonable price.

Electricity is an indispensable means of subsistence for people in today's society to enjoy modern civilized life and is also a necessary means of production for economic growth and improvement of people's life. Therefore, electric universal service is essentially a public welfare policy with income redistribution. Based on the basic connotation of electricity universal service, it should have the following basic characteristics. First, availability, or called universal, which means that all users should access to power access services. Second, the tilt, which means that the high-cost power supply areas and low-income groups in the enjoyment of electricity services are more favorable treatment. Third, affordability, which means that the price of electricity services should be reasonable, can be withstand by the majority of users. Fourth, protection, which means that the electric universal service is limited to the protection of basic living standards, the other demand beyond this range of electricity demand should be met through market mechanisms to fully reflect the scarcity of electricity commodities. Fifth, mandatory, which means that the electric universal service is a public welfare policy, the government should adopt laws and regulations or policies to ensure the effective implementation of the universal service goals.

\section{THE ECONOMIC ANALYSIS ON THE ELECTRIC UNIVERSAL SERVICES}

Electricity can be used for lighting, heating, refrigeration, which is the basic power source of a variety of household appliances, machinery and equipment, its use value is self-evident. At the same time, as a resource, the electricity is also scarce, so it meets the general characteristics of goods, which also can be applied to the basic analysis framework of market supply and demand for general merchandise (Figure I). Since the invention of electricity in the 1870s, it has also experienced the general evolution characteristics like many other commodities. At first, electricity had the features of luxury, the prices was high, and the market was limited to a small number of rich groups. Then, with the technical progress and large-scale production, supply costs continued to decline, and the sustainable economic development had also led to continuous improvement of social consumption power, the electricity consumer groups were growing, electricity has become a universal commodity. Therefore, the power industry was gradually organized in accordance with the idea of supply of goods, in many countries, it was transformed by a department of government to an independent market players, which improved the efficiency of electricity supply and market size, but still couldn't meet the needs of the market, which is interpreted as a phenomenon of the market failure by many of the current literature, in fact, it is not accurate, market failure refers to the existence of social benefits more than social costs, and enterprises are unwilling to supply the market range. The electric universal service refers to the need to provide electricity services to all users, for man users, the supply cost is greater than the social benefits, that the enterprises do not supply electricity to them is not belong to the scope of market failure.

An important aspect of the study of electric universal 
service is the determination of its service scope, which can be analyzed by means of the economic analysis framework shown in Figure I. In Figure I, D is the social demand curve of electricity, MR is the marginal revenue curve, $\mathrm{S}$ is the supply curve under natural monopoly organization, $\mathrm{S}^{\prime}$ is the supply curve of perfect competitive organization, and Q4 is the range of a country covering the scale of all users.

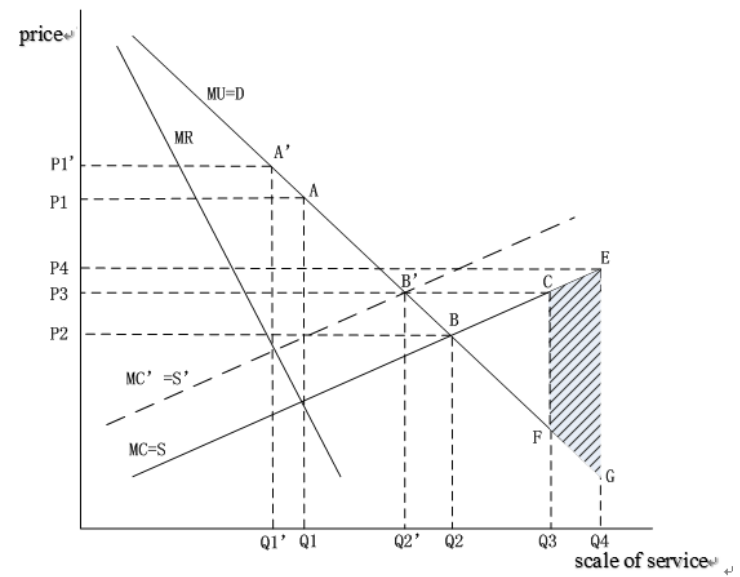

FIGURE I. THE ECONOMIC ANALYSIS ON ELECTRIC UNIVERSAL SERVICE

\section{A. The Necessity of "Monopoly Supply + Government} Regulation" Mode in Electric Industry

When the electric industry adopts the competitive organization form, the electric supply curve is MC ', and the enterprise finally achieves the equilibrium level $A^{\prime}$ ' based on the pricing principle of $\mathrm{MC}$ '= MR. the equilibrium price is $\mathrm{P} 1$ ', and the equilibrium supply scale is Q1 ', the market supply gap is Q1'-Q4, where Q1'-Q2 'is the scope of market failure, which can be eliminated by the government's control policy, and the scope of universal service is Q2'-Q4.

However, once the natural monopoly organization is chosen, the power supply curve MC is lower than MC' due to the avoidance of redundant construction and full use of economies of scale. That is to say, the natural monopoly organization is more competitive than competitive organization at any supply level, the final equilibrium price and equilibrium production were $\mathrm{P} 1$ and $\mathrm{Q} 1$. In the equilibrium, the market supply gap is Q1-Q4, of which Q1-Q2 is the market failure part, which can be eliminated by the government's control policy, and Q2-Q4 is the scope of universal power service. Comparing the two kinds of industrial organization and government regulation, it can be found that the "monopoly supply + government regulation" mode can effectively reduce the scale of the universal service.

\section{B. The Attributes of Electric Universal Service and the Scale of Cost Compensation}

In fact, the world's electricity supply generally take the "monopoly supply + government control" model. In this mode, the power supply cost is greater than the social benefit in Q2-Q4, because the users often live in high-cost remote areas, rural areas or other areas, the use of market mechanisms can not achieve power supply, so Q2-Q4 is the focus of universal power service range. From this point of view, electric universal service is essentially a public policy with relief nature, so in the implementation process it is need to adhere to the principle of non-profit, but need compensate the corresponding cost gap in the implementation of electric universal service. As the electric universal service is only limited to protect the basic electricity demand of the residents, that is to meet the electricity demand of ordinary lighting, TV, washing machine and so on, so the Q2-Q4 electricity supply cost gap compensation should be excluded from basic electricity demand part. But because of this part of the users are often living in backward areas, relatively poor, most of their electricity demand are in the basic electricity needs. Thus, in general, the cost gap for electric universal service is roughly the area of the triangle BEG.

\section{Optimize the Implementation Mechanism of Electricity Universal Service, Reduce the Scale of Cost Compensation}

The scope of universal power service and cost of compensation shown in figure 1 belong to the theoretical discussion, based on a high efficient implicit assumption, but in practice, it is difficult to distinguish the users of electric universal service and the basic electricity demand scale, so there is always efficiency loss of electric universal service, and to reduce this loss, it is need to optimize the mechanism design of electric universal service. This paper argues that it can proceed from two aspects:

First, for the Q3-Q4 part where the electricity supply cost is much greater than the social benefits, the government should co-ordinate the other universal service for comprehensive consideration, and take off-site relocation model. One of the important roles of electric universal service is to provide the necessary conditions for regional economic development, but there are often some very remote and backward areas, where the cost of providing electricity is very high, far greater than its social benefits. These areas are also often high-cost areas that provide universal services such as telecommunications, postal services, and highways. Moreover, even if these basic means of subsistence are realized in these areas, it is still difficult to achieve economic growth due to their poor economic conditions. On the whole, for these very high-cost areas, taking off-site relocation model may be a better choice, which can significantly reduce the cost gap compensation scale of the universal service. Among them, $C$ point is no difference point, where the size of compensation $\mathrm{CF}$ and the sum of relocation cost and the universal service cost after relocation are no diffidence.

The second is to take sub-file price model, effectively distinguish between non-key users of electric universal service and non-essential electricity demand. At present, the electricity price of resident users is low but the price of industrial and commercial users is high, mainly because of the cross subsidy of electricity price, but it does not make a scientific distinction among the residents. In other words, in fact, almost all of the residents in China now are enjoying the electric universal service, and the enjoying scale of electricity demand is beyond the basic electricity demand, which will inevitably lead to increased social burden, electric subsidies unreasonable and inefficient. In general, the scale of electricity consumption is positively correlated with the per capita income level. After determining the basic power consumption per capita, considering the average household population (for example, 3 for urban and 4 for rural), it is possible to determine the average Electricity 
demand, and as a basis for the implementation of sub-file price system. Specifically, when the household electricity consumption falls within the range of the basic demand, a low-price policy of less than the average supply cost is implemented, and if it exceeds the range, a multi-level high electricity price policy is executed which is higher than the average power supply cost. And ultimately achieve the goal of subsidizing the poor by the wealthy groups in residential electricity consumption, and effectively improve the efficiency of electric universal service.

\section{THE CONCLUSION}

The electric universal service is a national public welfare policy designed to ensure that non-discriminatory, reliable and affordable electricity services are available to all residents within a country. In this paper, the general economic analysis framework of electric universal service is constructed, the necessity of monopoly supply and government regulation is demonstrated, and the attribute of electricity universal service and the compensation scale of cost gap are analyzed. In addition, with the help of the economic analysis framework established in this paper, this paper proposes two ideas to optimize the electric universal service implementation mechanism. First, for the Q3-Q4 part where the electricity supply cost is much greater than the social benefits, the government should co-ordinate the other universal service for comprehensive consideration, and take off-site relocation model. The second is to take sub-file price model, effectively distinguish between non-key users of electric universal service and non-essential electricity demand.

\section{REFERENCES}

[1] Zhao Huiru, Li Chunjie, Li Hongze. Electric Universal Service in Electricity Market Environment [M]. Beijing: China Electric Power Press, 2009, P2.

[2] Tang Min. Jurisprudence Foundation and System Construction of Universal Service - Take electric power industry as an example [J]. Power Demand Side Management, 2010 (1).

[3] Chen Kejun. Interpretation of the Electric Universal Service and its Implementation conditions [J]. Volkswagen Electric, 2004 (2).

[4] Li Chuangjun. Electricity Universal Service Regulation: Origin, Task and Method [M]. China Economic Times, 2008-07-08 (05). 